\title{
Preparation and Sintering Effect in Quartz-Barium Titanate Porous Ceramics and Permeability Modulation Using an Implanted Electrode
}

\author{
Ernesto Suaste Gómez, José de Jesús Agustín Flores Cuautle, and Omar Terán Jiménez
}

Sección Bioelectrónica, Departamento de Ingeniería Eléctrica, Centro de Investigación y Estudios Avanzados del IPN, 07360 México, DF, Mexico

Correspondence should be addressed to Ernesto Suaste Gómez; esuaste@cinvestav.mx

Received 15 January 2014; Accepted 10 March 2014; Published 16 April 2014

Academic Editor: Peter Majewski

Copyright (C) 2014 Ernesto Suaste Gómez et al. This is an open access article distributed under the Creative Commons Attribution License, which permits unrestricted use, distribution, and reproduction in any medium, provided the original work is properly cited.

\begin{abstract}
Barium titanate and quartz mixed in different proportions were used to create porous piezoelectric ceramics. Three different sintering temperatures were used for the ceramics preparation; a nichrome wire was used as internal electrode in porous ceramics. Characteristics as porous area, porosity, and its relationship with quartz percentage and sintering temperatures were studied. Porous ceramics with an implanted electrode were created, by applying an alternating voltage in the internal electrode that controlled the liquid permeability coefficient, calculated by the Darcy Law.
\end{abstract}

\section{Introduction}

Piezoelectric ceramics should have high density in order to obtain good mechanical and piezoelectric responses, which means that porosity represents a fail; moreover, there are some fields where porosity is an advantage; examples of this are filtering, high temperature applications, and piezoelectric transducers where the target acoustic impedance is low [1]. Usually ceramic preparation is expensive and it is difficult to control its structural properties. This is the reason to research new methods to obtain ceramics is necessary. In the ceramics fabrications process is necessary to pay attention to the initial components, preparation, and sintering conditions, since those steps are essential to obtain specific properties in accordance with the desired applications [2]

Several methods have been proposed in order to obtain porous ceramics; sacrificial template method, replica technique, and direct foaming can be mentioned as examples of this [3-5]. In this paper, a method is proposed based on the combination of two different piezoelectric materials and their differences on densification processes and fusion temperatures, in order to obtain porous piezoelectric ceramics. By the use of adequate material proportions and suitable processing conditions it is possible to get porous ceramics in the microand nanofiltration [6].

Using metallic wire immersed in the ceramic as third electrode, it is possible to modify the dielectric constant in the ceramic; it is due to the domains concentration around the wire that magnifies the sensibility in the area near the electrode [7]. Some metallic materials used as third electrode in this ceramic kind are platinum $(\mathrm{Pt})$ and nichrome $(\mathrm{NiCr})$; these materials are used due to low chemical reactivity, stability in electric properties, high conductivity (electrical and thermal), and high fusion temperature [8-10]; a ceramic with third electrode called ceramic controlled piezoelectric offers the advantage that increases the analysis surface because the metallic implant works as third electrode [11-14].

\section{Materials and Methods}

2.1. Samples Preparation. The oxide method was used to obtain piezoelectric ceramics [15]. Barium titanate $\left(\mathrm{BaTiO}_{3}\right)$ and Quartz $\left(\mathrm{SiO}_{2}\right)$ with purity of $99 \%$ or more were used; ceramics were created with quartz in proportions of $20 \%$, $18.75 \%$, and $10.63 \%$, and these percentages were selected 
based on the mechanical resistance of final ceramics. All the raw materials and wire implants were obtained from Sigma Aldrich.

The particle size of the used compounds was controlled by sieving. Also mentioned compounds were mixed in controlled proportions and crushed in an agate mill for 40 minutes; polivinilic alcohol was added in a rate of $0.075 \mathrm{~mL}$ per gram of mixture; afterwards this mixture was pressed forming two layers: the first contains $\mathrm{BaTiO}_{3}$ and the second is a mixture of $\mathrm{BaTiO}_{3}$ and $\mathrm{SiO}_{2}$ in the rates previously mentioned, at $3500 \mathrm{~kg} / \mathrm{cm}^{2}$ in a circular mold to obtain samples with $10 \mathrm{~mm}$ diameter and $2 \mathrm{~mm}$ thickness. During the fabrication process and previous to the sintering stage $\mathrm{NiCr}$ wire was added in transversal form between layers. Samples were sintering in air with heat rate of $5^{\circ} \mathrm{C} / \mathrm{min}$ from room temperature to $600^{\circ} \mathrm{C}$, a stay of 30 minutes and new ramp with heat rate of $10^{\circ} \mathrm{C} / \mathrm{min}$ until final sintering temperature, and a final stay in the sintering temperature of $60^{\circ} \mathrm{C}$; finally the samples were cooled in natural way; in this form ceramics of two layers and immerse electrode were created as Figure 1 shows; three sintering temperatures were used: 800,1000 , and, $1200^{\circ} \mathrm{C}$. Ceramics without third electrode were created in order to serve as references.

The obtained ceramics were poled by applying an electric field of $1 \mathrm{kV}$ per millimeter thickness at $100^{\circ} \mathrm{C}$ in an hour silicone oil bath.

\section{Characterization}

In order to know the size and number of pores in sintered ceramics an optic microscope (DTM300) with coupled photographic camera was used. The obtained images were processed by the use of software (Ts View tucsen and NI Vision Builder $\mathrm{Al}$ ) as way to avoid measurement errors due to human perception.

By the use of theoretical density, porosity $p$ was calculated with

$$
\% p=\left(1-\frac{p_{m}}{p_{t}}\right) \times 100,
$$

where $p_{m}$ and $p_{t}$ are measured and theoretical densities, respectively.

The fine lands method was used to calculate the liquids permeability coefficient for ceramics with and without third electrode; the method consists of placing water in graded container sealed in its bottom with the element which will be characterized. Measuring the time used to reach certain altitude, by the use of Darcy law equation (2) [16], it is possible to get the liquids permeability coefficient. Figure 2 shows the experimental setup used to obtain this coefficient:

$$
\% p=\left(1-\frac{p_{m}}{p_{t}}\right) \times 100\left[\frac{\mathrm{cm}}{\mathrm{s}}\right],
$$

where $a$ is the burette area $\left(\mathrm{cm}^{2}\right), L$ is the ceramic thickness $(\mathrm{cm}), A$ is the ceramic area $\left(\mathrm{cm}^{2}\right), \mathrm{h}_{1}$ and $\mathrm{h}_{2}$ are the initial and final water altitude, respectively.

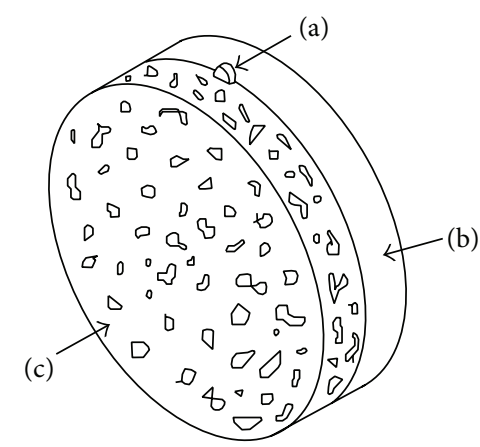

Figure 1: (a) NiCr electrode and porous ceramic with (b) $\mathrm{BaTiO}_{3}$ and (c) $\mathrm{BaTiO}_{3} / \mathrm{SiO}_{2}$ layers.

In the case of ceramics with third electrode, the experimental setup previously explained was used and the third electrode was exited with AC voltage with $5 \mathrm{~V}$ p-p amplitude and frequencies of $100 \mathrm{~Hz}, 500 \mathrm{~Hz}$, and $1 \mathrm{MHz}$ as Figure 2 shows.

\section{Results and Discussion}

Mixed oxide method was used to obtain porous ceramics, by using different sintering temperatures as well as different quartz proportion porous ceramics with different pore size, and as a result permeability coefficients were obtained and characterized.

Figure 3 shows ceramics photographs with $20 \%$ quartz, where it is observed that, by increasing the temperature, the number of pores decreases and its area increases; this is because at high temperature the number of grains decrease as a consequence of the compounds start to melting and make the ceramic structure more dense in some areas; low sintering temperatures can be considered incomplete sintering having as a consequence incomplete densification in both ceramic components.

Figure 4 shows the relation between pore area and pore number for ceramics sintered at $1200^{\circ} \mathrm{C}$ with quartz percentage of 18.75 and $20 \%$; it is possible to see that pore number as well as area increases for those ceramics that have superior percentage of quartz.

Samples porosity as function of sintering temperature is shown in Figure 5; it is possible to see the increment in porosity when sintering temperature increases for those ceramics containing 18.75 and $20 \%$ quartz, while for ceramics with $10.63 \%$ quartz porosity decreases when sintering temperature increases.

For ceramics with third electrode, liquids permeability coefficient was measured; Figure 6 shows the obtained coefficients when alternating voltage that was applied in the third electrode for ceramics sintered at $1000^{\circ} \mathrm{C}$ and quartz percentage of 10.63 and $18.75 \%$. It is clear that permeability coefficient for ceramics with $18.75 \%$ quartz is lower than for ceramics with $10.63 \%$ quartz; this is due to the density increment for this ceramics. 


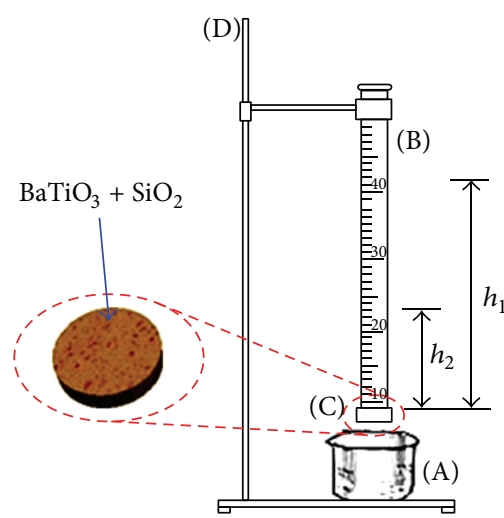

(a)

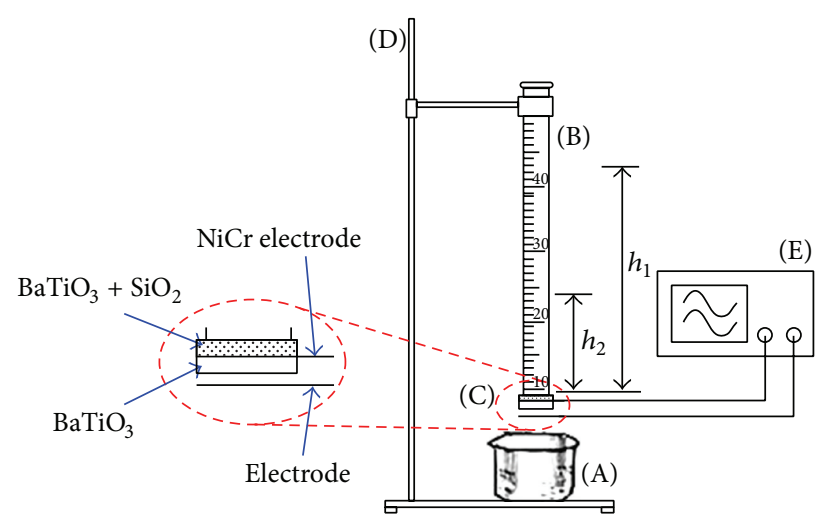

(b)

FIGURE 2: Experimental setup used to determine the liquids permeability coefficient, (a) porous ceramic without implant, (b) porous ceramics with implant; (A) container, (B) burette, (C) porous ceramic, (D) support, and (E) signal generator.
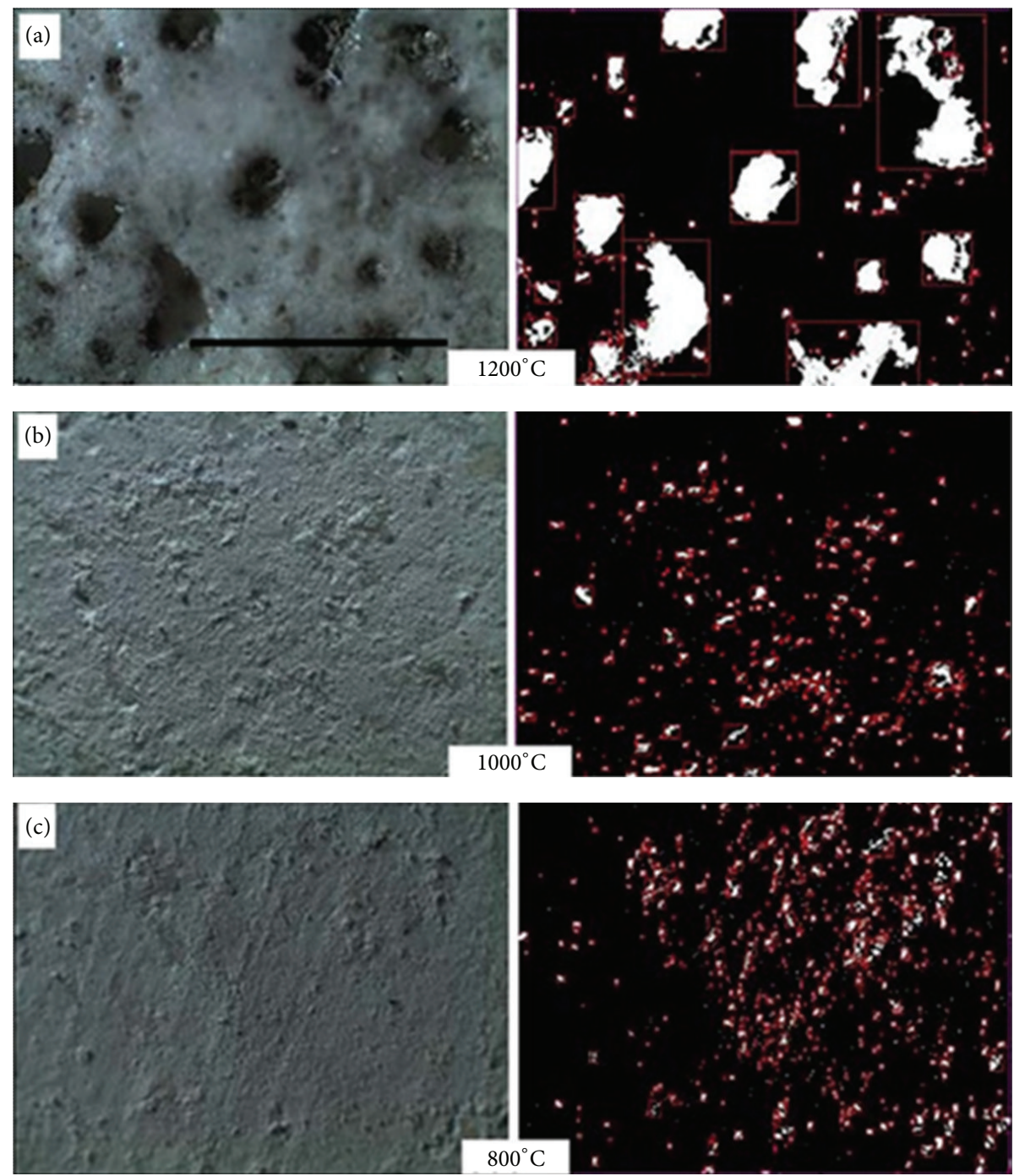

FIGURE 3: Ceramic digital photographs ( $\times 10)$ with scale bar 800 microns for sample with $20 \%$ quartz and sintering temperatures of (a) $1200^{\circ} \mathrm{C}$, (b) $1000^{\circ} \mathrm{C}$, and (c) $800^{\circ} \mathrm{C}$. 


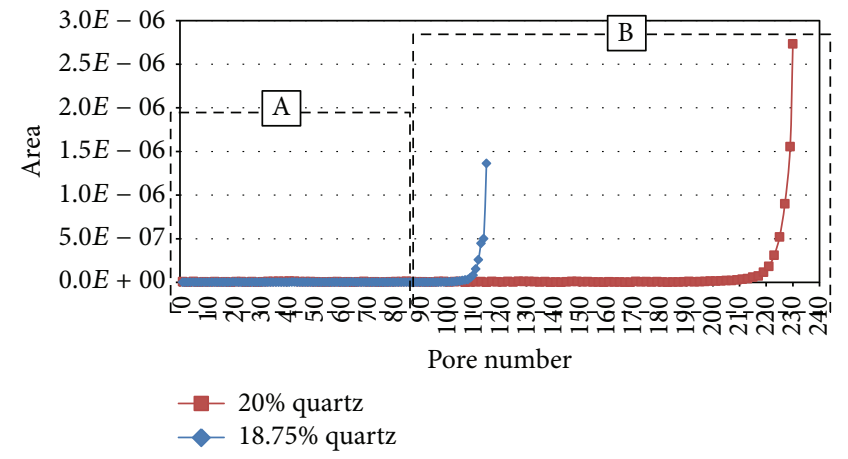

FIGURE 4: Area and pore number for ceramics sintered at $1200^{\circ} \mathrm{C}$.
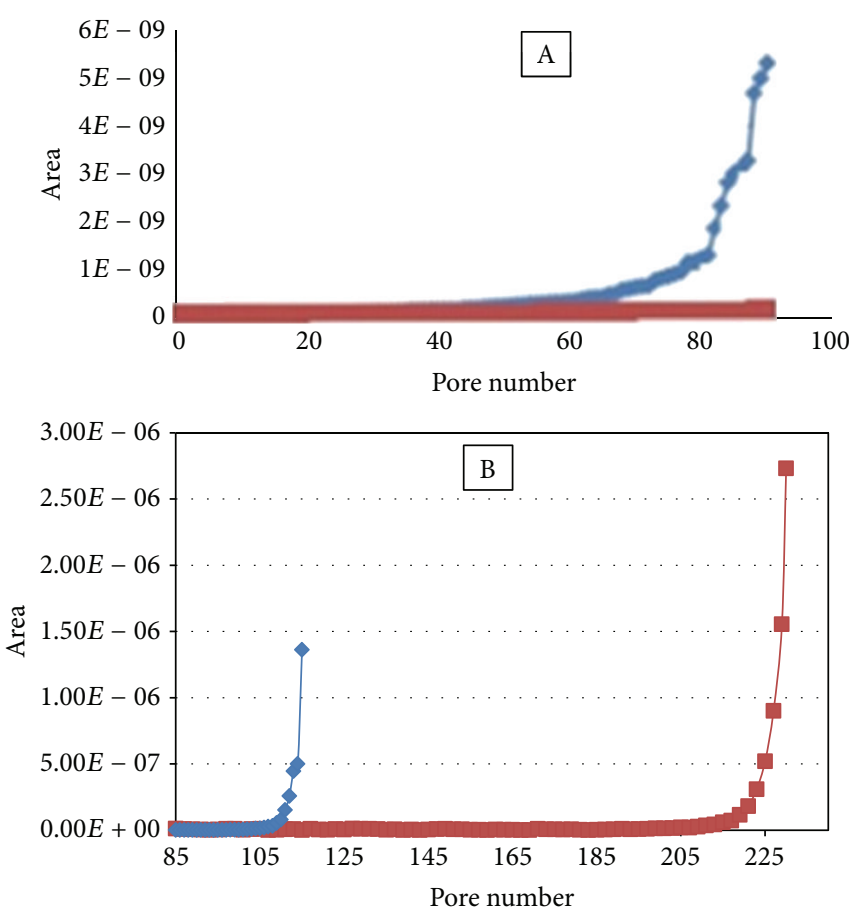

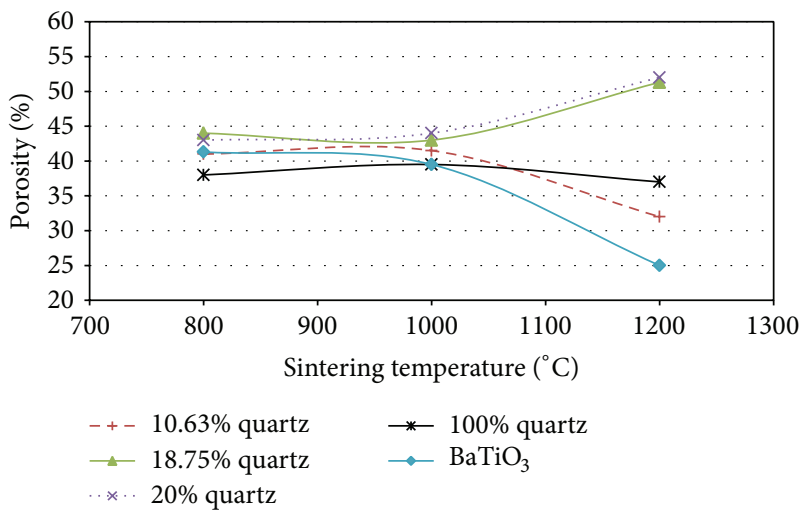

Figure 5: Porosity changes as sintering temperature function.

Figure 7 shows the liquids permeability coefficient for ceramics sintered at $1200^{\circ} \mathrm{C}$ and $10.63 \%$ quartz; the measurements point out that the highest liquids permeability coefficients were founded in ceramics sintered at $1200^{\circ} \mathrm{C}$ with a $10.63 \%$ percentage of quartz.

For ceramics stimulated with AC signal, it is important to point out that, in all cases, when the frequency of signal increases, the permeability coefficient increases; this is due to the fact that ceramic vibration allows increasing the liquid flux through the ceramic.

\section{Conclusions}

It was observed that it is possible to get porous ceramics by mixing $\mathrm{BaTiO}_{3}$ and $\mathrm{SiO}_{2}$ and changing the rates of the mixture as well as changing the sintering temperature. There is also a strong relationship between manufacture process and

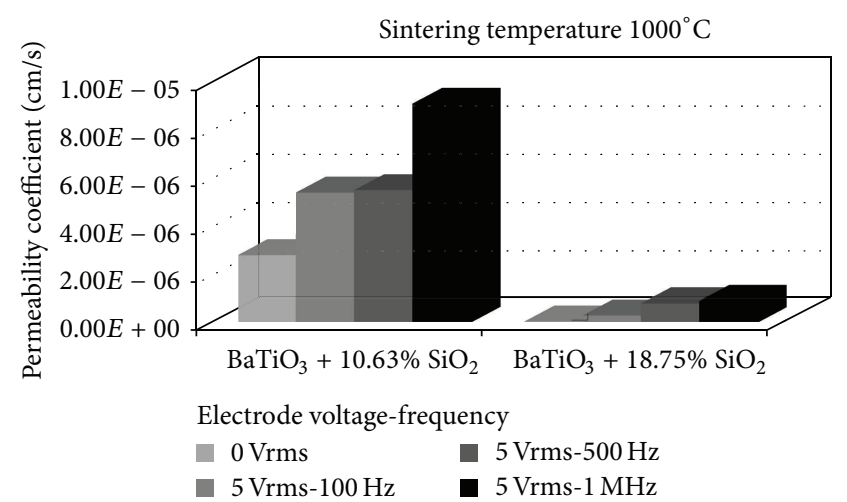

FIGURE 6: Liquids permeability coefficient for porous ceramic sintered at $1000^{\circ} \mathrm{C}$.

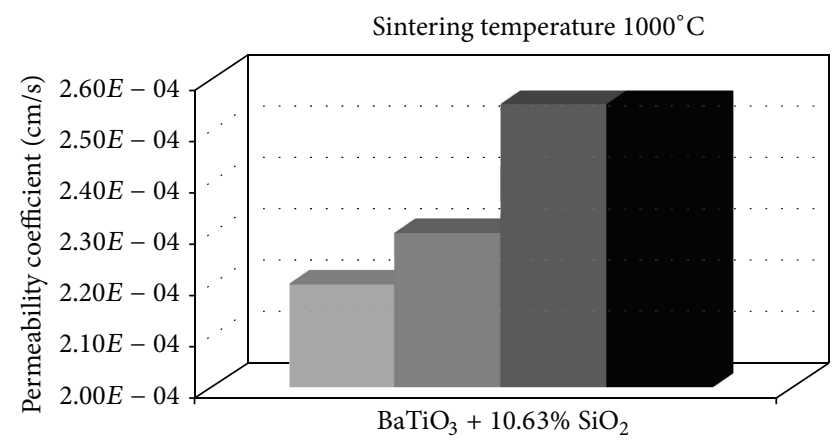

Electrode voltage-frequency
$0 \mathrm{~V}$
5 Vrms $-500 \mathrm{~Hz}$
$5 \mathrm{Vrms}-100 \mathrm{~Hz}$
$5 \mathrm{Vrms}-1 \mathrm{MHz}$

FIgURE 7: Liquids permeability coefficient for porous ceramic sintered at $1000^{\circ} \mathrm{C}$. 
physical ceramic properties like number and pore area and liquids permeability coefficient; obtained data is the base to develop porous ceramics adequate for different applications.

It is practical to modify the sintering temperature and rate of quartz used in the porous ceramic fabrication as a way to control the desired porosity in the ceramics and consequently its permeability coefficient.

In the case of ceramics without third electrode, it is not necessary to stimulate the ceramic; the temperature at which this kind of ceramic works is suitable not only for biomedical applications but also for industrial applications, as high temperature filter.

In the case of ceramics with metallic implant as third electrode by applying an AC signal, it is possible to modify the permeability coefficient by means of varying the signal frequency; this characteristic can be used for the development of controlled filters in many fields.

\section{Conflict of Interests}

The authors declare that there is no conflict of interests regarding the publication of this paper.

\section{Acknowledgments}

This work was supported in part by the Mexican Agency CONACyT through Grant 151894; one of the authors, José de Jesús Agustín Flores Cuautle, is grateful to CONACyT for a postdoctoral grant support.

\section{References}

[1] R. Narayan and P. Colombo, Advances in Bioceramics and Porous Ceramics, John Wiley \& Sons, New York, NY, USA, 2009.

[2] R. W. Rice, Porosity of Ceramics, Marcel Dekker, New York, NY, USA, 1998.

[3] H. Wang, X.-D. Li, J.-S. Yu, and D.-P. Kim, "Fabrication and characterization of ordered macroporous PMS-derived $\mathrm{SiC}$ from a sacrificial template method," Journal of Materials Chemistry, vol. 14, no. 9, pp. 1383-1386, 2004.

[4] T. Ohji and M. Fukushima, "Macro-porous ceramics: processing and properties," International Materials Reviews, vol. 57, no. 2, pp. 115-131, 2012.

[5] P. Colombo, "Conventional and novel processing methods for cellular ceramics," Philosophical Transactions of the Royal Society A: Mathematical, Physical and Engineering Sciences, vol. 364, no. 1838, pp. 109-124, 2006.

[6] Q. Xu and M. A. Anderson, "Synthesis of porosity controlled ceramic membranes," Journal of Materials Research, vol. 6, no. 5, pp. 1073-1081, 1991.

[7] C. O. González-Morán, J. J. A. Flores-Cuautle, and E. SuasteGómez, "Ferroelectrics: development, applications and potentiality in medical physics and electrical engineering," in Proceedings of the 11th Mexican Symposium on Medical Physics, vol. 1310, pp. 77-80, March 2010.

[8] Purdue University, Thermophysical Properties Research, C. and Y.S. Touloukian, Thermophysical Properties of Matter, the TPRC data series; a comprehensive compilation of data, IFI/Plenum, New York, NY, USA, 1970.
[9] Y. S. Touloukian, Thermophysical Properties of Matter, vol. 10, Springer, New York, NY, USA, 1995.

[10] E. Suaste-Gómez, C. O. Gonzalez Moran, and J. J. A. Flores Cuautle, "Ceramic-controlled piezoelectric: development, applications and potentiality in electrical and biomedical engineering," in Piezoelectric Ceramics, E. Suaste-Gómez, Ed., pp. 209-228, Intech, 2010.

[11] M. I. Acuautla-Meneses, J. J. A. Flores-Cuautle, and E. SuasteGómez, "Permeability behavior of porous piezoelectric ceramics prepared in layers in response at AC voltage on electrode implanted," Ferroelectrics, vol. 423, no. 1, pp. 111-115, 2011.

[12] E. Suaste-Gómez, J. D. J. A. Flores-Cuautle, and C. O. GonzálezMorán, "Opacity sensor based on photovoltaic effect of ferroelectric PLZT ceramic with pt wire implant," IEEE Sensors Journal, vol. 10, no. 6, pp. 1056-1060, 2010.

[13] E. Suaste-Gómez, "Porous ferroelectric ceramic as gas sensor base on $\mathrm{BaTiO}_{3} / \mathrm{SiO}_{2}$," Ferroelectrics, vol. 445, pp. 88-95, 2013.

[14] J. J. A. Flores-Cuautle, A. Cruz-Orea, and E. Suaste-Gómez, "Photopyroelectric microscopy of porous ceramics," International Journal of Thermophysics, vol. 33, no. 10-11, pp. 2139-2144, 2012.

[15] M. I. Acuautla-Meneses, J. J. A. Flores-Cuautle, and E. SuasteGómez, "Preparation and characterization of porous ferroelectric ceramics applying quartz with barium titanate," in International Materials Research Congress, Cancun, Mexico, 2010.

[16] G. F. Pinder and W. G. Gray, Essentials of Multiphase Flow and Transport in Porous Media, John Wiley \& Sons, New York, NY, USA, 2008. 

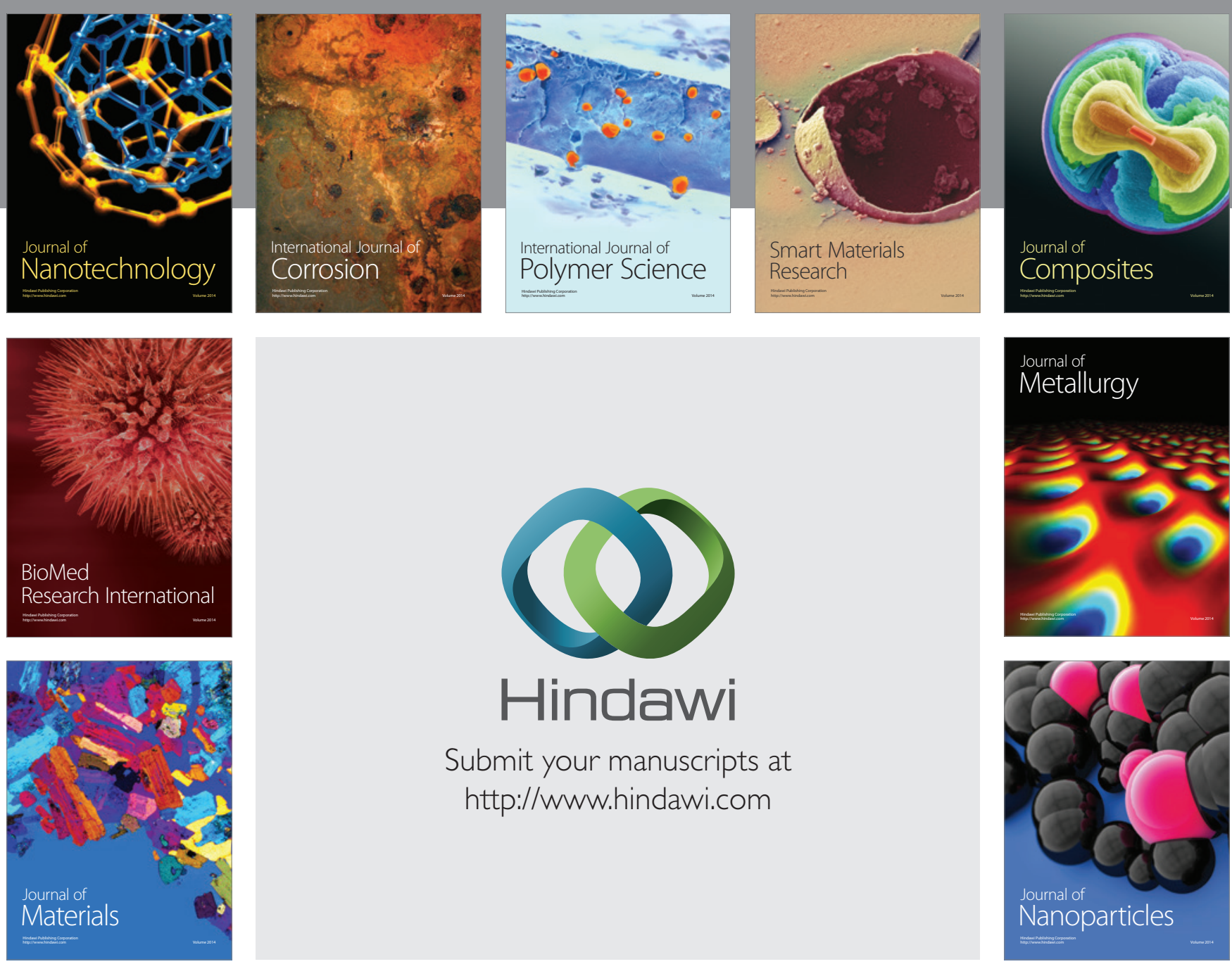

Submit your manuscripts at http://www.hindawi.com
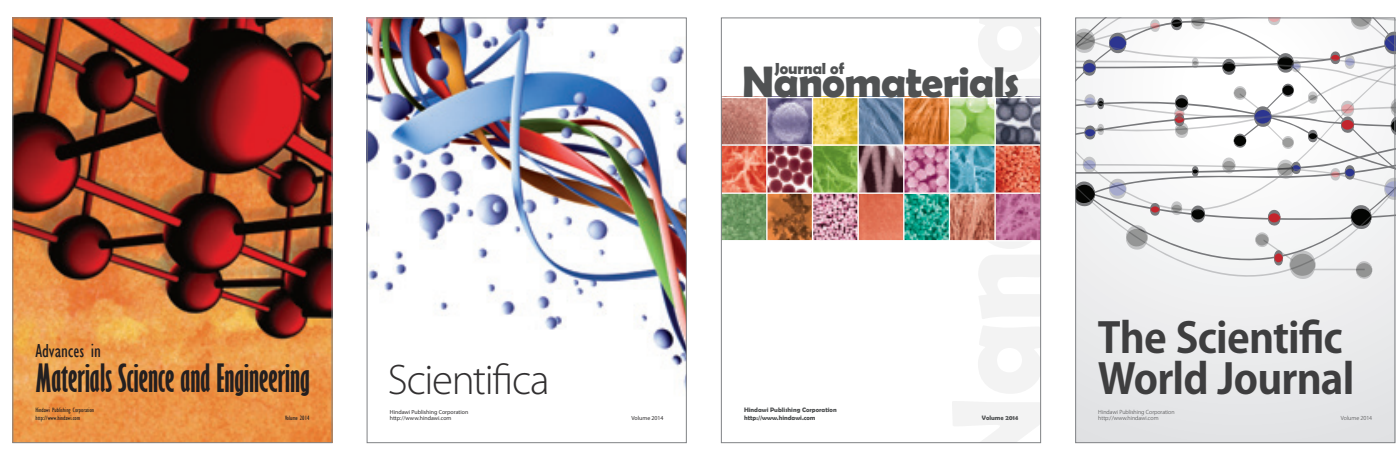

\section{The Scientific World Journal}
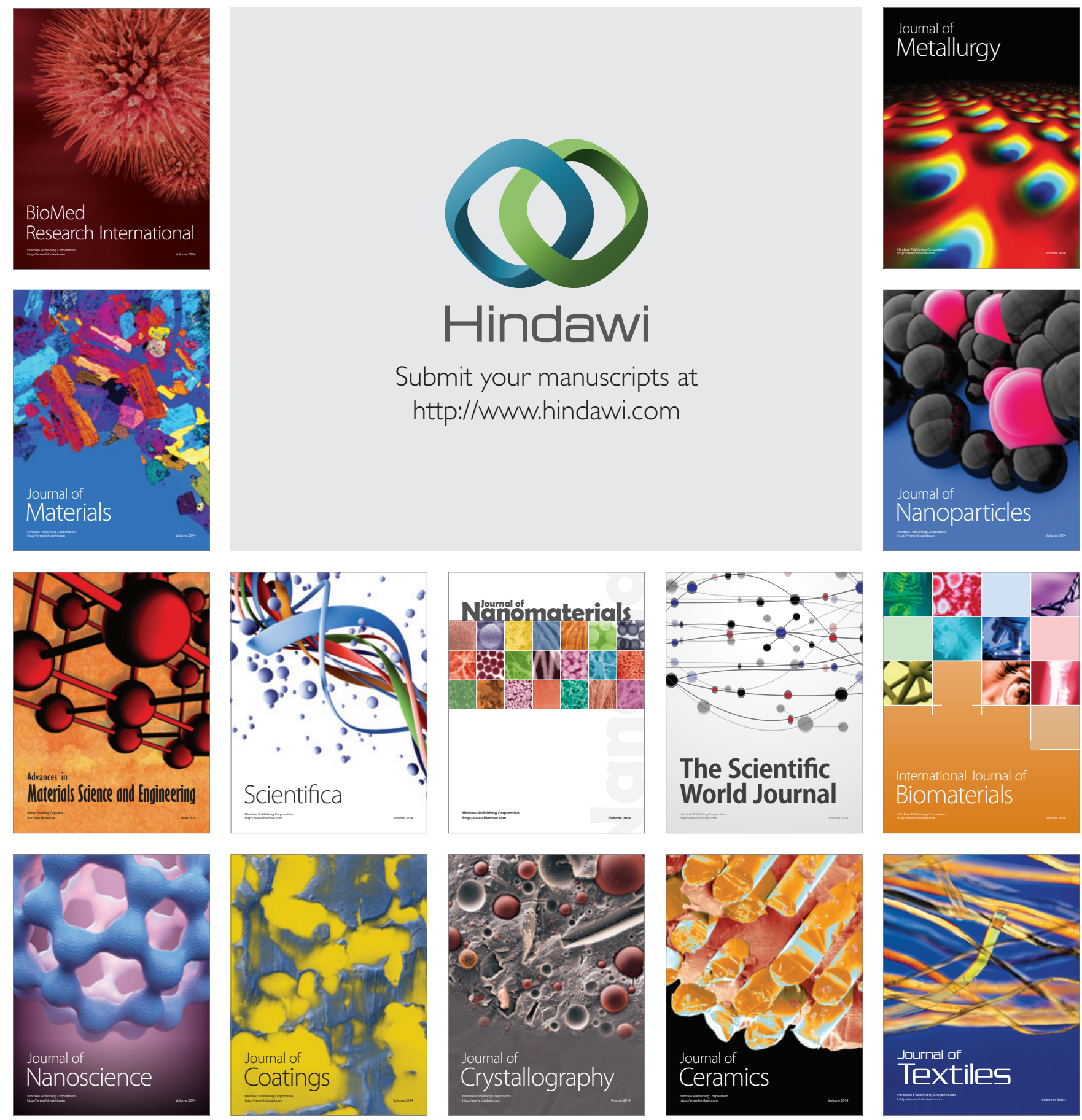